\title{
Stanniocalcin from an ancient teleost: a monomeric form of the hormone and a possible extracorpuscular distribution
}

\author{
Yutaka Amemiya *, Luciano E. Marra, Nazila Reyhani, John H. Youson \\ Departments of Anatomy, Cell Biology and Zoology and the Division of Life Sciences, University of Toronto at Scarborough, Scarborough, \\ Ont., Canada M1C $1 A 4$
}

Received 17 July 2001; accepted 11 November 2001

\begin{abstract}
Stanniocalcin (STC) is a homodimeric glycoprotein hormone implicated in calcium and phosphate regulation in both teleost fish and mammals. In the present study, immunostaining with salmon STC antiserum demonstrated that STC cells were localized in both the corpuscles of Stannius (CS) and in specific cells of the distal renal tubules of the silver arawana, Osteoglossum bicirrhosum, an ancient ray-finned fish (actinoptergian) and basal teleost (Order Osteoglossiforme). The morphology of these STC-immunoreactive kidney cells was similar to renal 'chloride' (mitochondrial-rich) cells. The immunoreactive renal cells were present in two of three other osteoglossiformes and absent in the gar, a nonteleost actinopterygian and the eel, another basal teleost. The arawana STC cDNA encodes a prehormone of 249 amino acids (aa) with a signal peptide of 31 aa and a mature protein of 218 aa. The deduced aa sequence of arawana STC shows $54-66 \%$ identity with other teleost STCs and $51-52 \%$ identity with mammalian STC-1. The deduced aa sequence of arawana STC contains ten cysteines, compared with 11 in teleost STC and in mammalian STC-1. The cysteine substitution occurs at the site of inter-monomeric disulfide linkage. Western blot analysis revealed a single $21 \mathrm{kDa}$ band under non-reducing conditions, and a single band of $25 \mathrm{kDa}$ under reducing conditions. These data indicate that arawana STC exists as a monomeric peptide. Northern blot analysis detected a $3.3 \mathrm{~kb}$ STC mRNA confined to the CS, with no hybridization signal in either the remaining kidney or in gut, muscle, brain and heart. The significance of the STC signal in cells of the renal tubules of arawana and two other Osteoglossiforme species requires further investigation. This is the first report of a monomeric form of STC in any vertebrate and the first evidence of STC in renal tubules of adult fish. (C) 2002 Elsevier Science Ireland Ltd. All rights reserved.
\end{abstract}

Keywords: Stanniocalcin; Corpuscles of Stannius; Renal; Osteoglossomorpha; Renal; Teleost; cDNA

\section{Introduction}

Stanniocalcin (STC), is the principal hypocalcemic factor originally associated only with the Osteichthyes (Wendelaar Bonga et al., 1985; Wagner et al., 1986; Lafeber and Perry, 1988). This glycoprotein hormone is synthesized and secreted by small kidney-associated endocrine glands referred to as the corpuscles of Stannius (CS). Recently, molecular cloning technologies have identified molecules with striking similarities to STC encoded in mammalian genomes (Chang et al., 1995; Wagner et al., 1995; Chang et al., 1996; Olsen et al., 1996) which also appear to play a role in mineral

\footnotetext{
* Corresponding author. Tel.: + 1-416-287-7404; fax: + 1-416-2877676.

E-mail address: amemiya@utsc.utoronto.ca (Y. Amemiya).
}

metabolism (Lu et al., 1994; Olsen et al., 1996; Wagner et al., 1997a). Interestingly, whereas the synthesis of piscine STC is confined to the CS, mammalian STC gene expression appears to be more wide spread and, therefore, the hormone may function in a paracrine rather than in an endocrine manner (Chang et al., 1995). Recently, Wagner et al. (1995), De Niu et al. (1998) demonstrated that certain cells of the human kidney are one likely source of immunoreactive STC. To date, no extracorpuscular sources of STC have been characterized in adult fishes.

Previous researches into the CS of fish suggested that they are embryologically derived from the pronephric and/or mesonephric ducts (Garrett, 1942; Kaneko et al., 1992). The bowfin (Amia calva) is the most ancient extinct species know to possess these glands and it has several hundred CS many of which have an intimate 
association with distal renal tubules (Youson et al., 1976). It has been suggested that this type of arrangement in the bowfin (holostean) reflects a more ancestral organization compared with the reduced number of more posteriorly distributed CS in the more modern bony fishes, the teleosts (Youson et al., 1976; Bauchot, 1953).

STC have been isolated and partially sequenced from several salmonid species (Wagner et al., 1986; Lafeber et al., 1988; Sundell et al., 1992) and the Australian eel (Butkus et al., 1987). The nucleotide sequence of STC mRNA and the deduced amino acid sequence have been reported from the Australian eel (Butkus et al., 1987) and coho salmon (Wagner et al., 1992). The complete amino acid sequence of STC isolated from chum salmon (Yamashita et al., 1995) has been elucidated. STC is a glycosylated homodimeric protein consisting of two identical, disulfide-linked polypeptide chains with a distinct primary structure among known proteins. The location of inter- and intra-molecular disulfide linkages in chum salmon has been determined (Hulova and Kawauchi, 1999). Chum salmon STC is a homodimer connected by a single inter-monomeric disulfide bond and it contains five intra-monomeric disulfide bonds.

The Osteoglossiforme order occupies a unique taxonomic position in the ray-finned fishes (Actinopterygii) in that it is intermediate to the early Neopterygii and the more recent Teleostei (Nelson, 1994). Since osteoglossiformes are among the most ancient order of the Teleostei division, an examination of their STC is interesting from both an evolutionary and a comparative viewpoint. An analysis of the ancient forms of the CS and STC is necessary in order to develop a conceptual framework for understanding not only the nature of this endocrine tissue and its product(s) but also for understanding both the phylogenetic and ontogenetic development of these elements in vertebrates.

The present study provides evidence for the presence of an extracorpuscular localization of STC in the osteoglossomorph, silver arawana (Osteoglossum bicirrhosum) and other osteoglossiformes. Furthermore, STC cDNA was cloned from the silver arawana and the deduced amino acid sequence of the STC revealed a heretofore unique substitution for a cysteine critical for inter-monomeric linkage.

\section{Materials and methods}

\subsection{Materials}

Adult silver arawana, $O$. bicirrhosum, and other osteoglossiformes (see below) were purchased from a commercial supplier (Toronto, Canada). The CS, kidneys and various control tissues [gut, brain, heart and muscle] from all the arawana and the species listed below were harvested and either fixed in Bouin's fluid for $24 \mathrm{~h}$ or frozen in liquid nitrogen and stored at $-80{ }^{\circ} \mathrm{C}$ until their use. Total RNA was extracted from the frozen tissues with TRIzol Reagent (Gibco) using the procedure specified by the manufacturer. CS from three other species of osteoglossiformes (butterfly fish, Pantodon buchholzi; featherfin knifefish, Chitala chitala; elephantnose, Gnathonemus petersii), the American eel (Anguilla rostrata), and the gar (Lepisosteus osseus) were also extirpated and fixed as above. CS was also collected from the white sucker (Catostomus commersoni ). The gar and white sucker were obtained from the Lake Ontario watershed.

\subsection{Immunohistochemistry}

The specimen tissues, were fixed for $24 \mathrm{~h}$ in Bouin's solution, dehydrated in a graded series of ethanols, and embedded in paraffin. Adjacent sections were cut at 7 $\mu \mathrm{m}$ thickness, mounted on glass slides and then deparaffinized, rehydrated and equilibrated in Trisbuffered saline (TBS) before subjecting them to the following procedures. The peroxidase-labeled[strept]avidin-biotin (Elias et al., 1986) staining method was used to localized the cellular sites of STC immunoreactivity. A 1:1000 dilution of chum salmon STC antiserum (Sundell et al., 1992) and the HISTOSTAINSP AEC immunostaining kit (Zymed Laboratories Inc., San Francisco, USA) was applied to some sections according to the manufacturer's instructions. A negative control on adjacent sections consisted of either, a similar dilution of antiserum which had been preabsorbed with salmon STC antiserum, preabsorbed with crude CS extract or substitution of the antiserum with either normal rabbit serum (NRS) or phosphatebuffered saline (PBS). Labeled tissue sections were counterstained with haematoxylin to enhance contrast. Adjacent, untreated tissue sections were also stained with the periodic acid-Schiff (PAS) technique as previously described (Marra et al., 1995).

\subsection{Immunocytochemistry}

The procedure for localization of STC immunoreactive cells in the CS has been previously described and involves protein-A gold (Marra et al., 1995). In order to characterize STC immunoreactive renal cells at the electron microscopic level, arawana kidney tissue proximal to the CS was excised and fixed in $4 \%$ paraformaldehyde and $0.1 \%$ glutaraldehyde in $0.1 \mathrm{M}$ phosphate buffer ( $\mathrm{pH} \mathrm{7.4)}$ for $3 \mathrm{~h}$. The tissue was then snap frozen in liquid nitrogen and cut at $50 \mu \mathrm{m}$ thickness using a vibratome. After the blocking of endogenous peroxidase actions and several buffer washes, the tissue sections were stained with anti-salmon STC 
(1:1000), incubated overnight at $4{ }^{\circ} \mathrm{C}$ in a moist chamber, followed by a 30 min incubation at room temperature with biotinylated secondary antibody (1:50) and then incubated for a further $30 \mathrm{~min}$ at room temperature with a peroxidase-antiperoxidase enzyme conjugate (1:50). Peroxidase activity was revealed by incubating the tissue sections in buffered $\mathrm{H}_{2} \mathrm{O}_{2}$ containing DAB. After the sites of immunoreactivity were visualized by a dissecting microscope, the tissue sections were trimmed of excess tissue, washed in PBS $(3 \times 10 \mathrm{~min})$, postfixed with $1 \% \mathrm{OsO}_{4}$ to enhance contrast, dehydrated, and embedded in an epoxy resin. The negative controls were as in immunohistochemistry.

\subsection{Western blot analysis}

Frozen CS were homogenized in PBS (pH 7.4) containing $5 \mathrm{mM}$ phenylmethylsulfonylflouride, centrifuged at $12000 \times g$ for $30 \mathrm{~min}$, and the supernatants pooled. The crude CS extract was diluted in SDS sample buffer $1: 1$, the proteins were separated by SDS polyacrylamide gel electrophoresis in $12 \%$ gels either in the presence, or in the absence, of reducing agents ( $\beta$-mercaptoethanol). The protein bands from the gel were electroblotted $(250$ $\mathrm{mA} 2 \mathrm{~h}$ ) onto a nitrocellulose membrane (Laemmli, 1971) and incubated with 1:6000 dilution of antiserum against chum salmon STC (Sundell et al., 1992) for 90 min at room temperature. This procedure was followed by an incubation in a 1:1000 dilution of peroxidaselinked donkey anti-rabbit gamma globulin. Immunoreaction was detected using a ECL Western blotting detection reagents kit (Amersham Pharmacia).

\subsection{PCR amplification}

\subsubsection{Internal partial cDNA clone}

Single-strand cDNA was prepared from the total RNA $(1 \mu \mathrm{g})$ at 42 for $60 \mathrm{~min}$ using Moloney murine leukemia virus reverse transcriptase accompanied with a Omniscript RT Kit (QIAGEN) and d(T) $)_{18}$ primer. All procedures were performed according to the manufacturer's manuals. The two primers, a forward primer A, 5'-GA(AG)GTICA(AG)GA(AG)GA(AG)TG(TC)TA$3^{\prime}$ and a reverse primer $\mathrm{B}, 5^{\prime}-\mathrm{TA}(\mathrm{AG}) \mathrm{TAIC}(\mathrm{TG})(\mathrm{AG})$ TTIGG(AG)AA-3', were designed on the basis of conserved aa sequences among the known STCs (Fig. 4). Using these primers, internal partial fragments of arawana STC cDNA were amplified with $1 \mu \mathrm{l}$ of the cDNA, 25 pmol of each primer, and $2.5 \mathrm{U}$ of HotStarTaq DNA polymerase (QIAGEN) in $50 \mu \mathrm{l}$ volume of Taq reaction buffer by polymerase chain reactions (PCR). The reactions were carried out after denaturation at $94{ }^{\circ} \mathrm{C}$ for $15 \mathrm{~min}$ for 30 cycles $\left(30 \mathrm{~s}\right.$ at $94{ }^{\circ} \mathrm{C}, 30$ $\mathrm{s}$ at $50{ }^{\circ} \mathrm{C}, 1 \mathrm{~min} 30 \mathrm{~s}$ at $72{ }^{\circ} \mathrm{C}$ ) and a final extension for $5 \mathrm{~min}$ at $72{ }^{\circ} \mathrm{C}$. The sample was rapidly cooled to $4{ }^{\circ} \mathrm{C}$ and analyzed on agarose gel.

\subsection{2. $5^{\prime}$ and $3^{\prime}$ partial $c D N A$ clone}

$5^{\prime}$ and $3^{\prime}$ regions of arawana STC cDNA were amplified using SMART RACE cDNA Amplification Kit (CLONTECH). Primer C, 5'-CTGAGCTACCTCTCCGATGG-3', was synthesized based on the nucleotide sequences of internal partial cDNA clone of arawana STC (Fig. 4). Primer C and an anchor primer provided in the kit were used for PCR. The reactions were carried out after denaturation at $94{ }^{\circ} \mathrm{C}$ for $15 \mathrm{~min}$ for 30 cycles $\left(1 \mathrm{~min}\right.$ at $94{ }^{\circ} \mathrm{C}, 30$ sat $55^{\circ} \mathrm{C}, 2 \mathrm{~min}$ at $72{ }^{\circ} \mathrm{C}$ ) and a final extension for $5 \mathrm{~min}$ at $72{ }^{\circ} \mathrm{C}$. Primer D, 5'-ACAGTATTCCTCACCTCCAC-3', was designed on the basis of the sequence of the $5^{\prime}$ partial clone of arawana STC cDNA (Fig. 4). Primer D and an anchor primer provided in the kit were used to amplify product by PCR as described above.

\subsection{DNA sequence analysis}

The PCR product was inserted into plasmid pCR II-TOPO or pCR XL-TOPO (Invitrogen) and subjected to sequence determination on both strands using Dye Terminator Cycle Sequencing Ready Reaction Kit (Applied Biosystem). To compensate for the errors associated with PCR, at least three independent PCRs including subsequent cloning and sequence analysis were performed on each 5'- and 3'-terminal region. All PCR products were sequenced on an ABI 377 automated DNA sequencer at the Hospital for Sick Children DNA sequencing facility (Toronto, Canada).

\subsection{Northern blot analysis}

Total RNA $(10 \mu \mathrm{g})$ from each of arawana CS, kidney, gut, heart, and brain were dissolved in $5 \mu \mathrm{l}$ of deionized water and $15 \mu \mathrm{l}$ of formaldehyde load dye (Ambion) was added. The RNA samples were incubated at $65{ }^{\circ} \mathrm{C}$ for $15 \mathrm{~min}$. The total RNA was electrophoresed on a $1 \%$ agarose $/ 6.6 \%$ formamide gel containing $1 \times$ MOPS buffer. The RNA was transferred to a nylon membrane and was fixed by microwave. The $5^{\prime}$ partial clone of arawana STC cDNA was labeled with $\left[{ }^{32} \mathrm{P}\right] \mathrm{dCTP}$ by random priming. The membrane was hybridized for $16 \mathrm{~h}$ at $42{ }^{\circ} \mathrm{C}$ and washed twice at room temperature in $2 \times$ SSPE containing $0.1 \%$ SDS for 10 min followed by two further washes at $60{ }^{\circ} \mathrm{C}$ in $0.1 \times$ SSPE containing $0.1 \%$ SDS for $20 \mathrm{~min}$. After the final washing the membrane was exposed to X-ray film at $-80{ }^{\circ} \mathrm{C}$ for 2 days.

\section{Results}

\subsection{Immunohistochemistry (Fig. 1a, b)}

The CS had a connective tissue capsule which separ- 
ated them from the surrounding renal tissue and which ramified the parenchyma as septa. The connective tissue also contained the neuro-vascular elements. Epithelial cells, grouped into lobules, made up the glandular parenchyma. The PAS reaction (results not shown) demonstrated the gland cells to be of variable staining intensity but the cytoplasmic granules of the majority of cells stained positively. In adjacent sections, cells immunoreactive to the probing antibody (Fig. 1b) were closely correlated with those cytoplasmic areas stained by the PAS technique and the results were similar to those previously described (Marra et al., 1992, 1994, 1995). Immunoreactivity of the cells confirms the corpuscles as the CS. The specificity of the immunolabelling was confirmed by the low levels of background staining in the surrounding supporting tissue (Fig. 1b) and by the abolition of the reaction in the CS and in almost all adjacent tissues under control conditions. These results are indicative of the specificity of the chum salmon STC antiserum for the gland cells of the CS of the arawana.

Interestingly, it was also noted that certain cells of the distal renal tubules were also STC immunoreactive (Fig. 1a). In light of these results we attempted immunohistochemistry, under the same conditions described, on Bouin's-fixed renal tissue from the ancient Neopterygii, the gar (L. osseus), the basal teleost, the American eel (A. rostrata) and on three other species of osteoglossomorpha (butterfly fish, $P$. buchholzi; feather- fin knifefish, $C$. chitala; elephantnose, $G$ petersii ). No extracorpuscular STC-like immunoreactivity was noted in eel, gar or elephantnose but the butterfly fish and featherfin knifefish had immunoreactive cells in the distal renal tubules. The low levels of background staining in the surrounding connective, vascular, and nervous tissues was indicative of the specificity of the chum salmon STC antiserum for the STC-immunoreactive renal cells. The positive staining reaction was abolished in adjacent sections when the primary antiserum was preabsorbed with salmon STC.

\subsection{Immunocytochemistry (Fig. 2a, b)}

When the gland cells were treated with the chum salmon STC antiserum in order to localize STC, gold particles were exclusively localized over the secretory granules of the CS cells (Fig. 2b). STC immunoreactivity was abolished in the CS cells by preabsorbing the probing antibody with salmon STC or substituting NRS or PBS in place of the chum salmon STC antiserum, indicating that these cells were STC-specific. The diffuse distribution of the STC-immunoreactive cells required that we use an immunological procedure that permitted identification of cells in the light microscope before embedding and preparation for electron microscopy. In kidney tissues from arawana which had been incubated in the primary antibody and then again in $\mathrm{DAB}$, reaction product was primarily localized in the
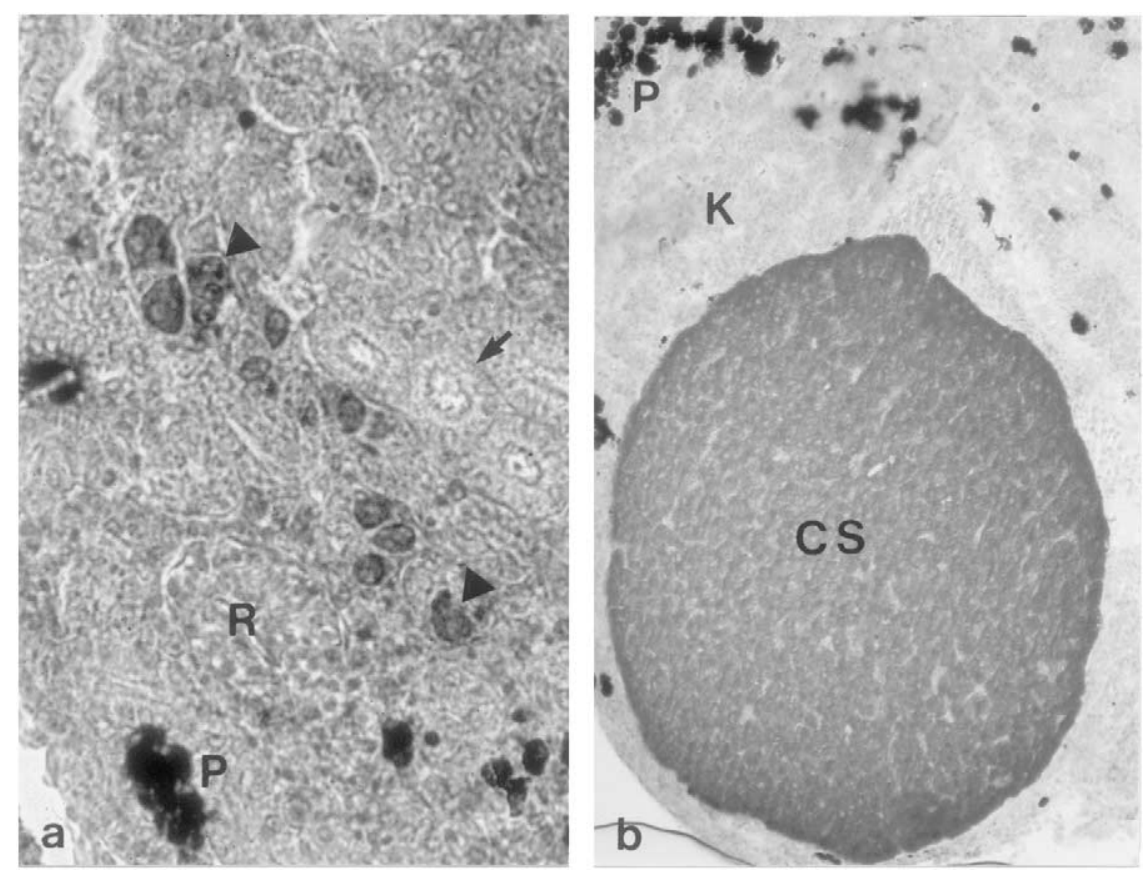

Fig. 1. Immunohistochemical localization of stanniocalcin (STC) in kidney (a) and corpuscle of Stannius (b) of arawana (Osteoglossum bicirrhosum) with anti-chum salmon STC serum. (a) Immunoreactivity of cells of the distal renal tubules (arrowheads) but not proximal tubules (arrow) or the renal corpuscle (R). P, pigment. $\times 500$ (b) Intense immunoreactivity in a corpuscle of Stannius (CS) but not in the surrounding kidney (K). P, pigment. $\times 40$. 

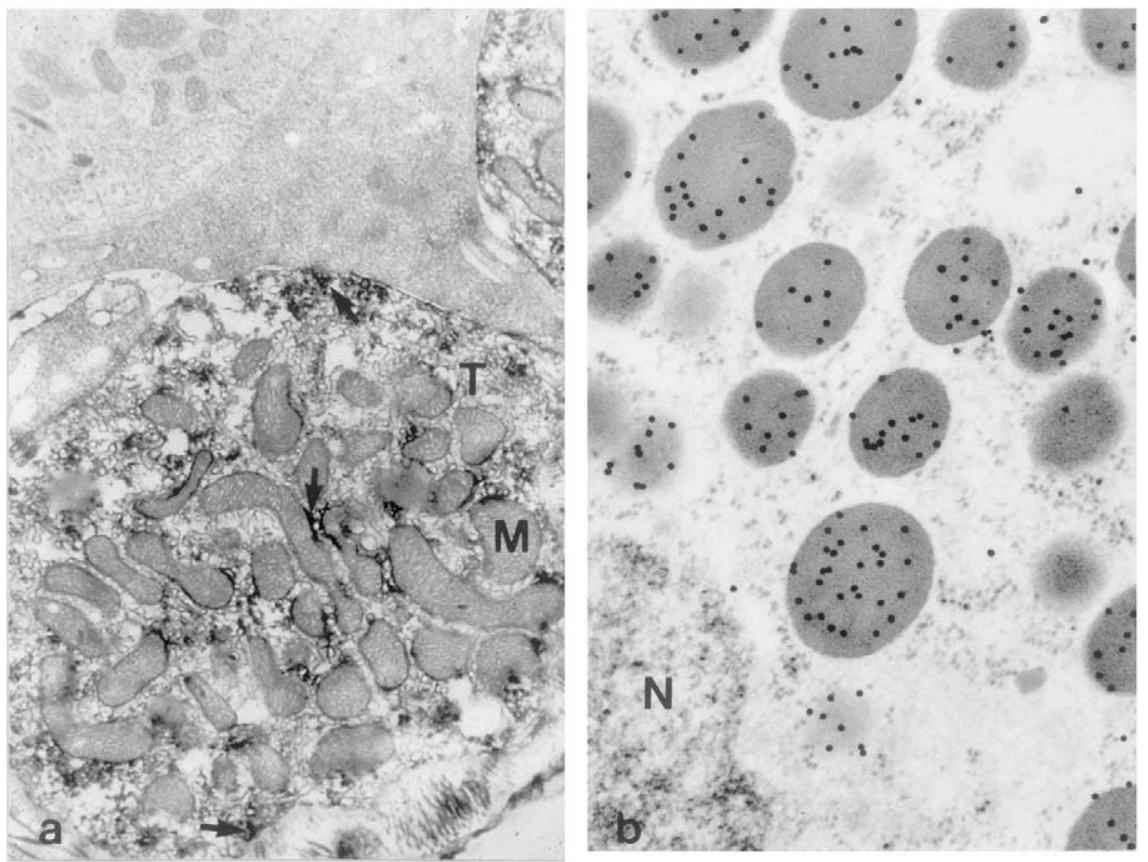

Fig. 2. Immunocytochemical localization of STC in kidney (a) and corpuscle of Stannius (b) of arawana (O. bicirrhosum) with anti-chum salmon STC serum. (a) Portions of several cells from a distal tubule with only those containing smooth tubules (T) and many mitochondria (M) showing the electron-dense labeling (arrows) for STC. $\times 25000$. (b) The granules of the cells in the corpuscles of Stannius localize gold particles. N, nucleus. $\times 30000$.

cytoplasm of specific cells of the distal renal tubules (Fig. 2a). The cells were characterized by an abundance of mitochondria and smooth tubules. Cells of similar description have been termed mitochondria-rich cells or renal chloride cells in the kidney of other ray-finned fish (Youson and Butler, 1988). Adjacent cells, with few mitochondria and smooth tubules, were devoid of reaction product. The reaction product in the cells of the distal renal tubules was primarily localized as electrondense deposits in the cytoplasmic matrix or associated with mitochondrial, tubular or plasma membrane. No reaction product was present in the mitochondrial matrix, in the tubular lumina or in any secretory granules. Only a minor deposition of reaction product was noted on collagen fibrils of the extracellular matrix and the endothelium of sinusoids below the reactive renal cells. Negative controls showed no reaction product.

\subsection{Western blot analysis}

Western blot analysis of arawana and white sucker CS extracts yielded distinct immunoreactive bands (Fig. 3 ). Under reducing conditions the putative arawana STC monomer migrates with an apparent molecular weight of $24 \mathrm{kDa}$ whereas white sucker STC monomer migrates as a $29 \mathrm{kDa}$ band. Under non-reducing conditions, the white sucker STC exists as a dimer with a molecular weight of $48 \mathrm{kDa}$. However, in arawana, a single $21 \mathrm{kDa}$ band was found under non-reducing conditions (Fig. 3). This immunoreactive product in arawana represented a single monomer since it is similar in size to the white sucker momomer.

\subsection{Cloning and sequencing analysis of STC $c D N A$ for Arawana}

Three clones, which were amplified by PCR spanned the complete arawana STC cDNA (Fig. 4). Primers A

\section{Arawana White sucker}

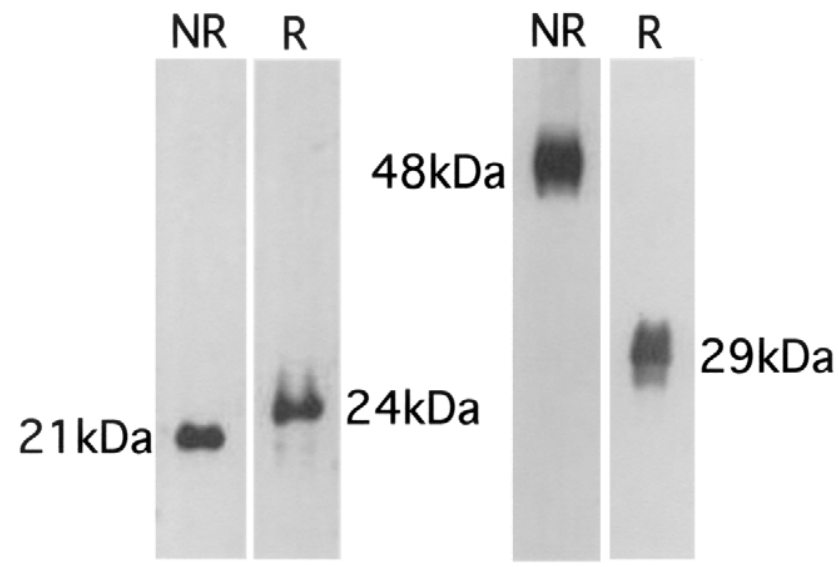

Fig. 3. Western blot analysis of corpuscle of Stannius (CS) extracts $(100 \mu \mathrm{g}$ protein per lane) from arawana (O. bicirrhosum) and white sucker (Catostomus commersoni ) under nonreducing (NR) and reducing $(\mathrm{R})$ conditions. 
primer D

ATCCCTGG ACAGIA'I'I'C C'ICACCI'CCACACGGACATCTCTTCCACAGTCTAAAGAAGAAACCTTTTTT TGTGAAGGTCGCTTGCTGACAGTAACCATGATCCAGAATGCATGCTTCTCCTGCTCTTT

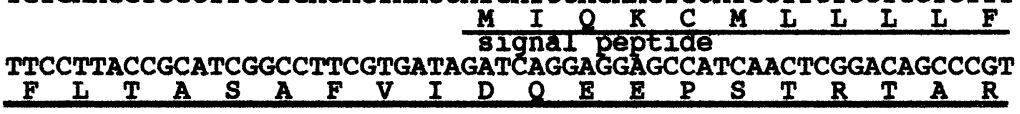

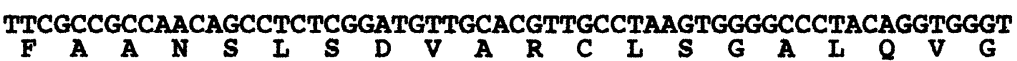

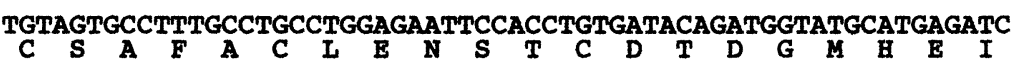

308
40

TGCAAGACCTTCCTCTACACAGCTGCAAAATTTGACACTCAGGGCAAAACCTTTGTCAAG

368

$\underset{\mathbf{E}}{\text { GAGAGCCTCCGCTGCATGGCTAATGGCATCACTTCCAAGGGCTTCTTGATGGTGCGTCGC }} \mathbf{T}$

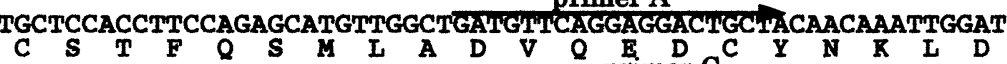

428
80

CTCTGTGGGGTGGCACGTGCCAACCCGGAGGCCATCGGAGAGGTAGCTCAGCTGCCCAAC $L C G \underset{\text { primer }}{\mathbf{V}} B^{R}$ AGCIICCCCAACAGGCACIATAGCACATTGCTGCAGAGTCTTCTAGAGTGCGACCAGGAG

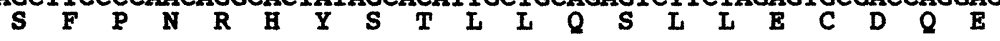
ACTGTGAGTCTAGTGAGGGACAGTATGTCTGCCAGGTTGGGGCCCGAGGTGGCTATGCTC TTCAAACTTCTCCAGAGCAGTTCTCGCTCTGGCTCCGCCGCTCAAGCTAGCAACAACGAT

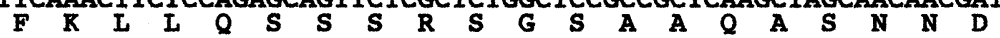

TAATGCGGTGCTCCATCACAGGTGGGGGAGAGCTGTCTTACACGCGTGCCATTCCCTCA GGCAAAATGATTCCCCCGGTGTGTGTCTGTTAGTGTGTGTACAAACAAATCGCCTGTAGA GACAATAGGATTAGGAGTTTGGTGACAGGATTGCCTTGAGTGGCATCATTTGTCTTGCTG AGTCTCACTCAGCATTCA CTAACATGTTCATGAAACAAATACACTGCTGCATGGGCCCC CCCACTCATCTAGGGTACTGCTGACTTCACGAAATGTACCCTTGCATATACAGTGCATAA AAAGAATTATTCACTTATTTCAGTAGACTATGTTCCTGTAA GTATTAAGAAATTAAAGGA GCTAAGGTATTGGAATTTAATTGGCCGAATCACCTTTTCAATGGGAAGCTTCGATTTAGG TACCTGGTGGTGTGAGTAATATAAGACGAGAGTCCATGGGCTAATCCACAGGAAACAGGT CTTAGGTGGTTTAAATGTGGGTTTACAACAGTGGATCTTCCAGGCAGATTACCTAATGTG GTTCTGAAAAGGCAGCCATTAGTATTTGGCTGCATAGAACATGGTACAAACTGGTACAAA TGCAGCACCACCAAGTTCCAACCGCAGCGTTTCCAGATTTTACAGAGCTGTTACTTGCCT GTTTAAGAAGTCTTGCTGGTAAATGATAATTATTTATTTTCCTACATAAATGTAATTCAT CTTACCTGAATAATTTTATTTTGGAGAATTTEGAAGTTTTTGCTATGTTGCGCTTCTGAA GCAGAGTCTATGCTGGTTATGGAGAACTGTATAAGTGGTCGTTTCATTATACCTGCAGAG CTGCATATAAACACAGAAGGGGCAAGGAGCACAAGTAGGTGAGGAAGCCAGAGTGAAGAT CTGCACGCTCTTCACAACTTTGTCTTATTTGTTCATTTACTCCTTTAACTTATGCTTTTC TCCAAAGCGACTAACAATGTTAAGGTCCTTATAGTTAACAAAGTCTCAAAAGTCTTGTGA CCATCAAGTCCTCTGGTTAAGTTCCTACAAATGAAAAAGTGTGACTCAGAGGTGGCTTTT GCAACCCAAAAGACAAATTGCGCTTGACTTGCATTTGAACCTCACTATTTTTGCCATTTC AGCTGTGTGCAGAAATGACCACTTTTTCAAAGGGGGAGATAGCTATTGAACGTTGTTTGA CTGCTGAGTGGTCATCAACATGAACCCGCTTTCTTGTTATAAGACTTCAGATGGGAACAA TGTTTGACAACCAAAGCATCACAGGGCAAACCTTCTCCTCACACCTTGCAGTGATGCTTA CAGGACCTCCTGCTTGGCACATTCAACACTGCTACCAATTAGTGGAAACGAATGACTCTT GATGTTCCTGTAGACATCCTCTGTGACCAAATTGTACGACACAGTTGTGTGGCATATAAG AGGATGTCCCCGACCCGAACAACATCTTTTCCATGAAAGTCACACTTAACAAGCCACCAA TGATCCAAGCCATTGGTACCTCTGCTAGTCGGAACGCTATTTGCACAGAGTCTAGAAGAG TCTTTGTGGTGTTTAAACTAAGCAGGTTGCCTAGGAGACAGTGTCTTGAGGGTGCTTTGA AAGACTGTTTCTTGTGGGTTATTCAAACCCAGAAGCCTTTTTGTTCTTAAATCAGTCACT TTTCCAACAAGGTTTTTTTTTTTTTTTTTTTTCCTTTAACCAAATGATCCACTACTCTTTTG AGTGCTGAACTTGTTCACCAGTCAGTGAAGGAACAATCTTTCTCTCCTCCTGCTGATGTT GAGTTGCAGCACTGGGGCACCATTTAGCCTGGGTTAATAATGTAATAATCAGCTTATTTTT TGTGCCACTCTGTTGCAGCTGTGTATTTACAACCATGAAAGAAAATGTCTGTTGTTTGAC TGAAAACAAATAATGATCATATCTGGTATATGGCATG-POLY(A)

908
968
1028
1088
1148
1208
1268
1328
1388
1448
1508
1568
1628
1688
1748
1808
1868
1928
1988
2048
2108
2168
2228
2288
2348
2408
2468
2528
2588
2648
2708
2768
2807

Fig. 4. Nucleotide sequence of arawana STC cDNA excluding poly-A tail and the deduced amino acid sequence (Accession number AB060558). Numbers of nucleotide and amino acid sequences are indicated at both sides. The deduced amino acid sequence of the proposed preSTC is numbered by designating a predicted N-terminus of STC as 1 . The signal peptide is underlined. Arrows show the direction and position of the four primers (A, B, C, D). A double underline shows the polyadenylation signal. The asterisk shows the stop codon.

and $\mathrm{B}$ amplified in PCR a cDNA corresponding to base numbers between 476 and 551 from arawana CS cDNA (Fig. 4). This clone was identified from its deduced amino acid sequence to encode an internal region of arawana STC cDNA which is well conserved among known STCs. Based on the nucleotide sequence of this internal region, primer $\mathrm{C}$ was synthesized for amplifica- tion of the 5'-terminal region. PCR, using primer $\mathrm{C}$ and an anchor primer, amplified a 5'-terminal region including base numbers $1-519$. PCR, using primer D and an anchor primer, amplified a 3'-terminal region including base numbers 28-2807. These PCR-amplified cDNAs provided the entire sequence of arawana STC cDNA (Fig. 4). The arawana STC cDNA consisted of 2807 
nucleotides (nt) excluding the poly (A) tail (Fig. 4). The STC cDNA is composed of $95 \mathrm{bp}$ in the $5^{\prime}$-untranslated region, $747 \mathrm{bp}$ coding for the preSTC, and $1965 \mathrm{bp}$ in the 3' untranslated region. The hexanucleotide AATAAA is the typical polyadenylation site located 15 nt upstream of the poly (A). The open reading frame of arawana STC cDNA encodes 249 aa residues. Sequence comparison with preSTCs from ray-finned fishes (Butkus et al., 1987; Wagner et al., 1992; Yamashita et al., 1995) reveals that the first 31 aa sequence of arawana pre STC is a signal peptide. Accordingly, arawana STC is composed of 218 aa residues. The deduced amino acid sequence shows that the arawana STC contains ten cysteines at positions 12, 21, 26, 32, $41,65,81,95,102$ and 173 , whereas the other teleost STC and mammalian STC-1 have 11 cysteines (Fig. 4). The codon for Arg169 in arawana STC is CGC and a change in the first nucleotide to $\mathrm{T}$ forms Cys (Fig. 4). Arawana STC has a $N$-glycosylation site at position 29-31 (Asn-Ser-Thr). The position of the glycosylation site is common in STC across all species.

\subsection{Northern blot analysis}

Northern analysis detected a $3.3 \mathrm{~kb}$ STC mRNA expression in the CS (Fig. 5). The value is comparable to the size of the STC cDNA (2807 nt) without the poly (A) tail. No hybridization signal is apparent in either the kidney, gut, muscle, brain, or heart (Fig. 5). These results suggest that expression of the arawana STC mRNA is confined to the CS.

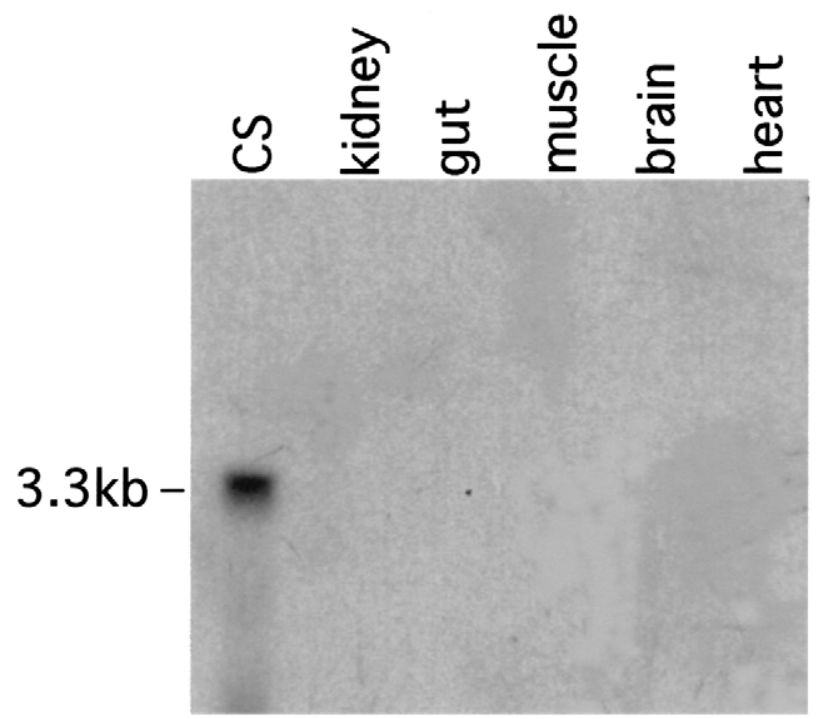

Fig. 5. Northern blots of total RNA isolated from corpuscles of Stannius (CS), kidney, gut, muscle, brain and heart from arawana. RNA was hybridized with a ${ }^{32} \mathrm{P}$-labelled, $5^{\prime}$ partial clone of arawana STC(1-519). Equal loading of lanes was confirmed by staining with ethidium bromide.

\section{Discussion}

This is the first report of renal STC-like immunoreactivity in adult vertebrates that possess a corpuscle of Stannius (CS).

In the bowfin, an holostean actinopterygian with ancient linkage to teleosts, several hundred CS are scattered throughout the kidney (Youson et al., 1976), many in close association with renal tubles. Immunoreactivity to the anti-salmon STC is localized within the CS of the bowfin and not in the renal tubules (Marra et al., 1992). In mammals, STC immunoreactivity is localized to certain cells of the kidney (Wagner et al., 1995), but there are no CS. The present results on renal STC may be significant from an evolutionary viewpoint since the STC immunoreactive profile which we now describe among the Osteoglossomorpha may represent an intermediate phylogenetic arrangement between the more ancient vertebrates and those with a more modern lineage. The results are also connected to the ontogenetic history of the CS. Recent research on the ontogeny of the CS (Kaneko et al., 1992) suggests that the CS develop from individual cells that first appear among the epithelial cells of the embryonic nephric ducts. If there is a renal origin for the CS of osteoglossomorpha, the adult renal cells although not synthesizing STC appear to have the ability to concentrate this hormone.

The immunoreactivity in the renal epithelium is localized to membrane and cytoplasmic matrix of cells that do not have secretory granules and cell organelles reflecting a high rate of protein synthesis and secretion. In contrast, the presence of STC-like immunoreactive cells with an ultrastructure similar to renal chloride (mitochondrial-rich) cells suggests a role of the hormone in renal ion movement. Support for this view is found in the now established role of STC in renal phosphate movement in both fish and mammals ( $\mathrm{Lu}$ et al., 1994; Wagner et al., 1997a,b). It has been implied that renal chloride cells of the bowfin might be expected to be involved in mineral metabolism and reflect the marine origins of this holostean (Youson and Butler, 1988). Osteoglossiformes are exclusively freshwater in nature, and, therefore, phosphate homeostasis would be a definite challenge. A renal source of STC would be an asset to this aspect of mineral metabolism and may be important to the phylogenetic development of the Osteoglossomorpha. It is noteworthy, however, that one of the osteoglossomorpha, elephantnose, did not show STC immunoreactivity in the kidney tubules. Whether there is either a physiological or phylogenetic significance to this variance requires further analysis. In addition, it must be established whether the intense immunoreactivity for STC on or near the membrane of these renal cells reflects STC which is free or bound to a STC receptor. 
Interestingly, whereas STC-immunoreactive cells were localized in the distal kidney of the arawana (Figs. 1 and 2), no hybridization signal on the Northern blot is apparent in the kidney (Fig. 5). There are a number of possible explanations for this result. First, there are too few STC-immunoreactive cells found in the kidney tissue. It is assumed that this inability to detect STC mRNA in kidney was related to sensitivity since it is difficult to estimate the relative content of the STC mRNA in the kidney tissue. Second, it is possible that there may be a different form of STC molecule in the kidney, and as a result, it could not be detected using the STC probe which we used. Recently, two cDNAs encoding proteins, STC-1 and STC-2, homologous to fish STC have been identified in humans and rodents (Chang and Reddel, 1998). Wagner et al. (1998) demonstrated the presence of two forms of STC in the Atlantic salmon and Verbost et al. (1993) gave strong evidence for two bioactive principles in the CS of both tilapia and rainbow trout. However, at present, it is difficult to say whether these STC isoforms represent differential posttranscriptional processing of the STC message or the expression of more than one STC gene-related product. Third, it is possible that arawana STC mRNA was not expressed in the kidney. When attempts to detect STC mRNA by Northern blot failed, we performed RT-PCR to detect the mRNA. Several different conditions for RT-PCR were used with the primer $\mathrm{C}$ and $\mathrm{D}$ but no signal was obtained (methods and data not shown). It is assumed that renal STC-immunoreactive cells have the receptor for STC so that STC antibody actually binds to the STC that has bound to the STC receptor. Given the morphology of the immunoreactive renal cells and our Northern blot analysis of renal and other tissues, we tend to favor the view that extracorpuscular expression of STC mRNA does not take place in Osteoglossomorpha species.

The arawana STC shows the highest aa sequence identity (Fig. 6) with the Australian eel (66\%), compared with the coho salmon $(63 \%)$, chum salmon (54\%), mouse STC-1 (52\%), human STC-1 (51\%), mouse STC-2 $(27 \%)$, and human STC-2 $(25 \%)$. It is noteworthy that the highest sequence identity is between elopomorpha (eel) and osteoglossomorpha (arawana), for both are basal teleosts (Nelson, 1994).

Our previous results suggested that on the basis of PAS positive staining of the CS, arawana STC may indeed be glycosylated (Marra et al., 1995). The position of the glycosylation site in arawana (Asn29Ser30-Thr31) is common to STC across all species examined to data.

It has been noted that fish STC and mammalian STC-1 have 11 cysteine residues located in the same position (Hulova and Kawauchi, 1999). The cysteine at position 169 is important for the establishment of a disulfide linkage between two monomers. Arawana
STC, however, contains only ten cysteine residues because Cys169 is replaced by arginine (Fig. 6). This result indicates that the arawana STC probably exists as a monomeric form, reflecting the presence of an even number of cysteine residues in the mature protein. In chum salmon, for example, the homodimeric character of STC is confirmed by establishing the intermonomeric disulfide linkage at Cys169. Five disulfide linkages, between Cys12-Cys26, Cys21-Cys41, Cys32Cys81, Cys65-Cys95, and Cys102-Cys137, fold the peptide chain of the STC monomer into five loops (Hulova and Kawauchi, 1999).

Western blot analysis confirmed the unusual substitution of the Cys residue and the existence of the arawana STC molecule as a monomer. In a previous study (Marra et al., 1998), we reported three non-reduced bands (approximately 56, 61, and $64 \mathrm{kDa}$ ) from crude CS extracts of white sucker. Under the more carefully controlled, non-reducing conditions of the present study, the white sucker STC exists as a dimer with a molecular weight of $48 \mathrm{kDa}$ (Fig. 3). It was previously known that the monomers bonded through a disulfide bridge. Under reducing conditions, the disulfide bond between the two monomers is reduced thereby giving a single band at $29 \mathrm{kDa}$ (Fig. 3). This compares with the 28-32 kDa diffuse band under reducing conditions reported previously (Marra et al., 1998). However, in arawana, a single $21 \mathrm{kDa}$ band was found under nonreducing conditions. This represented a single monomer since it was much smaller than the expected dimeric value. Under reducing conditions, a $24 \mathrm{kDa}$ band was found (Fig. 3). This increase in molecular weight under reducing conditions likely represented a linearization of the STC monomer through the reduction of the intramolecular disulfide bonds. Interestingly, Western blot analysis using a polyclonal anti-salmon STC or antitrout STC as the probing antibodies, previously demonstrated that an arawana STC immunoreactive protein migrated at approximately $68 \mathrm{kDa}$ under non-reducing conditions (Marra et al., 1995). Preabsorption of the salmonid STC antibodies with crude arawana CS extract abolished the immunoreactive bands (Marra et al., 1995). In the present study, we could not detect this form. Theoretical calculations of the molecular size of arawana STC cDNA showed it to be $23.8 \mathrm{kDa}$. Since a band lower than $21 \mathrm{kDa}$ did not exist under reducing conditions, this confirmed that the arawana STC exists as a monomer.

In summary, we have identified STC-like immunoreactivity in the CS and certain cells of the distal renal tubules of the arawana. However, the expression of arawana STC mRNA is confined to the CS. An explanation for the renal tubular immunoreactivity for STC requires further study. Western blotting indicates that arawana STC is a monomeric protein. Moreover, the 

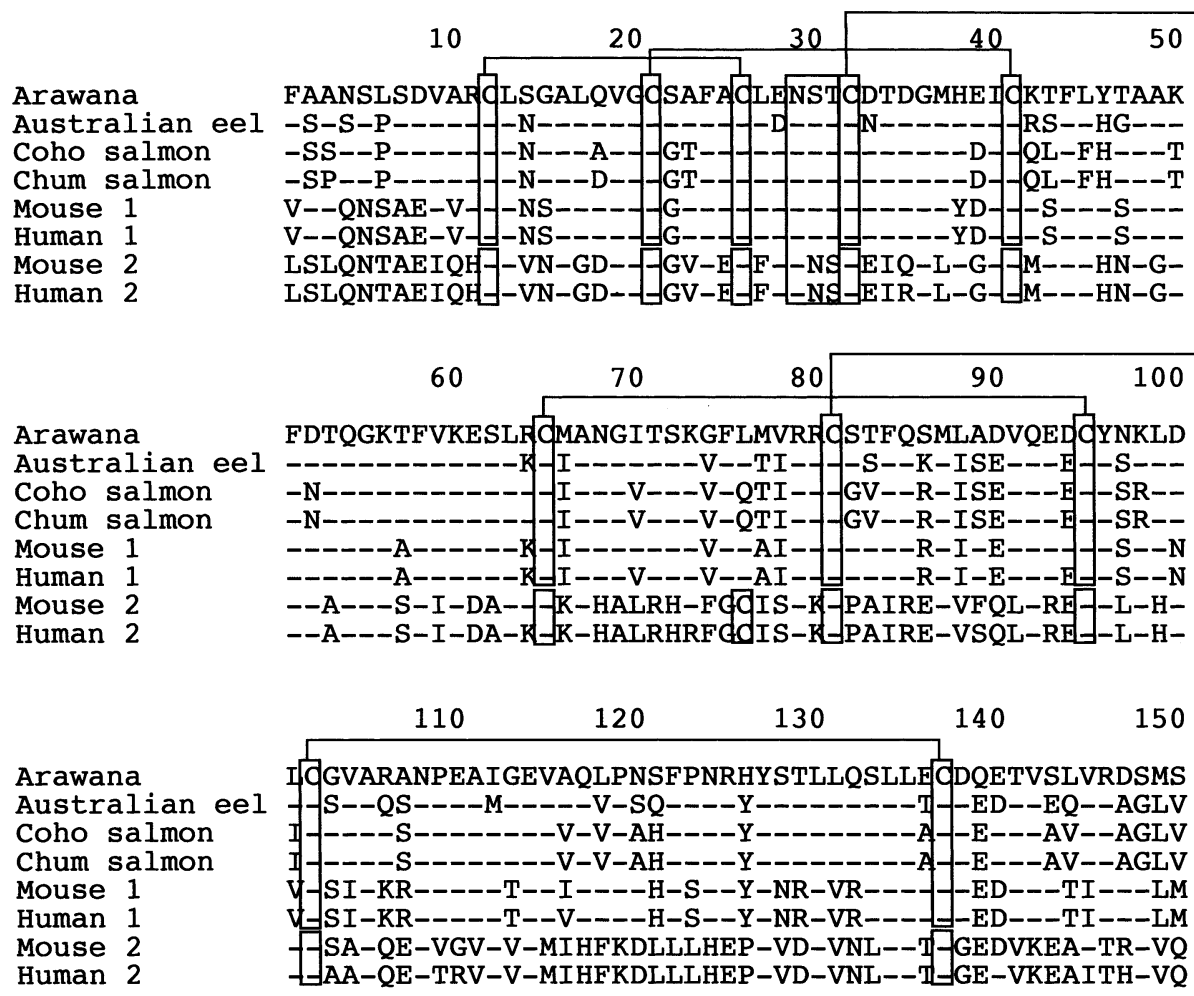

$160 \quad 170$ (dimer) $180 \quad 190 \quad 200$

Arawana ARLGPEVAMLFKLLQSSSR SGSAAQASNNDDYKAAGRWPLG*PLTFKIQP Coho salmon ----DMET--Q---NKH PPQGSN-GP-SAPAG**W---M-S-PS----Chum salmon Mouse 1 Human 1 Mouse 2 Human 2 -----DMETP-Q---NKH $-Q G S N-G P-S$ EKI--NM-S--HI--TDH AAQTHPR-DF-RRRTNEPQKLKVLLRNLRGEG EKI--NM-S--HI--TDHQAQTHPR-DF-RRRTNEPQKLKVLLRNLRGEE - $d$ dEQSWGG-CSI-SF TTSNIQRPPTAAPEHQPL-D-AQ-SR-HHRDTDH VDdEQNWGS-CSI-SEQTSAIQKPPTAPPERQPQVD-TK-SRAHHGEAGH

$\begin{array}{llllll}210 & 220 & 230 & 240 & 250 & 258\end{array}$

$\begin{array}{ll}\text { Arawana } & \text { NIHNRDPNHLLAKKRAVSE } \\ \text { Australian eel } & \text {-LRS---T--F----ST-S } \\ \text { Coho salmon } & \text { SMRG---T--F-R--S-EALERVME } \\ \text { Mouse } 1 & \text { DSPSHIKRTSQESA } \\ \text { Human } 1 & \text { DSPSHIKRTSHESA } \\ \text { Mouse } 2 & \text { HL***** TANRGAKGERGSKSHPNAHARGRTGGQSAQGPSGSSEWEDEQSEYSDIRR } \\ \text { Human } 2 & \text { HLPEPSSRETGRGAKGERGSKSHPNAHARGRVGGLAQGPSGSSEWEDEQSEYSDIRR }\end{array}$

Fig. 6. Amino acid sequence of arawana STC compared with STCs from Australian eel (Butkus et al., 1987), coho salmon (Wagner et al., 1988), chum salmon (Yamashita et al., 1995), mouse STC-1 (Chang et al., 1996), human STC-1 (Chang et al., 1995), mouse and human STC-2 (Chang et al., 1998). Gaps (asterisks) are introduced to maximize the sequence identity. Dashes indicate amino acids identical to those of arawana STC. A common glycosylation site (positions 29-31) is boxed. The positions of Cys residues are marked by boxes and the five common disulfide linkages are indicated. The site of inter-monomeric linkage is designated (dimer) but in arawana cysteine is replaced by arginine.

deduced amino acid sequence from arawana STC cDNA shows that arawana STC lacks the cysteine residue which is essential to create the inter-monomeric disulfide linkage to produce the homodimeric protein. The arawana STC molecule seems to be unique among the vertebrate STCs that have been studied to date. It remains to be determined whether this monomeric feature reflects the antiquity of the STC molecule (or the species) and whether it has any significance to biological activity.

\section{Acknowledgements}

This study was supported by a grant from the National Sciences and Engineering Research Council (NSERC) of Canada to J.H. Youson L.E. Marra was supported by a NSERC Graduate Fellowship. The authors are grateful to the following individuals who provided technical assistance, advice or material during the course of the investigation, J.A. Heinig; H. Kawauchi; F.W. Keeley; R. Or; and K. Paramsothy. 


\section{References}

Bauchot, R., 1953. Anatomie Comparee des corpuscles de Stannius chez les Teleosteens. Arch. Zool. Exp. Gen. 89, 147-149.

Butkus, A., Roche, P.J., Fernley, R.T., Haralambidis, J., Penschow, J.D., Ryan, G.B., Trahair, J.F., Tregear, G.W., Coghlan, J.P., 1987. Purification and Cloning of a corpuscles of Stannius protein from Auguilla australis. Mol. Cell. Endorcinol. 54, 123-133.

Chang, A.C., Reddel, R.R., 1998. Identification of a second stanniocalcin cDNA in mouse and human: stanniocalcin 2. Mol. Cell. Endocrinol. 141, 95-99.

Chang, A.C., Janosi, J., Hulsbeek, M., de Jong, D., Jeffrey, K.J., Noble, J.R., Reddel, R.R., 1995. A novel human cDNA highly homologous to the fish hormone stanniocalcin. Mol. Cell. Endocrinol. 112, 241-247.

Chang, A.C., Dunham, M.A., Jeffrey, K.J., Reddel, R.R., 1996. Molecular cloning and characterization of mouse stanniocalcin cDNA. Mol. Cell. Endocrinol. 124, 185-187.

De Niu, P., Olsen, H.S., Gentz, R., Wagner, G.F., 1998. Molecular cloning and characterization of stanniocalcin-related protein. Mol. Cell. Endocrinol. 146, 137-140.

Elias, L.B., Ramain, G., Hu, J., Amir, A., 1986. Observation of single-mode operation in a free-electron laser. Phys. Rev. Lett. 28 (57(4), 422-427.

Garrett, F.S., 1942. The development and phylogeny of the corpuscles of Stannius in ganoid and teleostean fishes. J. Morphol. 70, 41-67.

Hulova, I., Kawauchi, H., 1999. Assignment of disulfide linkages in chum salmon stanniocalcin. Biochem. Biophys. Res. Commun. 257, 295-299.

Kaneko, T., Hasegawa, S., Hirano, T., 1992. Embryonic origin and development of the corpuscles of Stannius in chum salmon (Oncorhynchus keta). Cell. Tissue Res. 268 (1), 65-70.

Laemmli, U.K., 1971. Clevage of structural proteins during the assembly of the hed of bacteriophage T4. Nature (London) 227, 680-685.

Lafeber, F.P., Perry, S.F., 1988. Experimental hypercalcemia induces hypocalcin release and inhibits branchial $\mathrm{Ca}^{2+}$ influx in freshwater trout. Gen. Comp. Endocrinol. 72, 136-143.

Lafeber, F.P., Hanssen, R.G., Choy, Y.M., Flik, G., Herrmann-Erlee, M.P., Pang, P.K., Wendelaar Bonga, S.E., 1988. Identification of hypocalcin (teleocalcin) isolated from trout Stannius corpuscles. Gen. Comp. Endocrinol. 69, 19-30.

Lu, M., Wagner, G.F., Renfro, J.L., 1994. Stanniocalcin stimulates phosphate reabsorption by flounder renal proximal tubule in primary culture. Am. J. Physiol. 267, R1356-R1362.

Marra, L.E., Youson, J.H., Butler, D.G., Friesen, H.G., Wagner, G.F., 1992. Stanniocalcin-like immunoreactivity in the corpuscles of Stannius of the bowfin, Amia calva L. Cell Tissue Res. 267, 283-290.

Marra, L.E., Youson, J.H., Wendelaar Bonga, S.E., Hanssen, R.J.G.M., Wagner, G.F., 1994. Immunoreactivity of the corpuscles of Stannius of the garpike, Lepisosteus osseus, to antisera against salmon and trout stanniocalcins. Cell Tissue Res. 277, $511-518$.
Marra, L.E., Groff, K.E., Youson, J.H., 1995. The corpuscles of Stannius in arawana (Osteoglossum bicirrhosum), an ancient teleost. Tissue Cell 27 (4), 425-437.

Marra, L.E., Butler, D.G., Zhang, D.H., Oudit, G.Y., Youson, J.H., 1998. Corpuscles of Stannius and stanniocalcin-like immunoreactivity in the white sucker (Catostomus commersoni): evidence for a new cell-type. Cell Tissue Res. 293 (1), 155-164.

Nelson, J.S., 1994. Fishes of the World, Third ed. Wiley, New York.

Olsen, H.S., Rosen, C.A., Vozzolo, B.L., Jaworski, E.M., Wagner, G.F., 1996. Human stanniocalcin, a possible hormonal regulator of mineral metabolism. Proc. Natl. Acad. Sci. USA 93, $1792-$ 1796.

Sundell, K., Bjornsson, B.T., Ito, H., Kawauchi, H., 1992. Chum salmon (Oncorhynchus keta) stanniocalcin inhibits in vitro intestinal calcium uptake in Atlantic cod (Gadus morhua). J. Comp. Physiol. (B) 162, 489-495.

Verbost, P.M., Butkus, A., Atsma, W., Willems, P., Flik, G., Wandelaar Bonga, S.E., 1993. Studies on stanniocalcin: characterization of bioactive and antigenic domains of the hormone. Mol. Cell. Encdocrinol. 93 (1), 11-16.

Wagner, G.F., Hampong, M., Park, C.M., Copp, D.H., 1986. Purification, characterization, and biossay of teleocalcin, a glycoprotein from salmon corpuscles of Stannius. Gen. Comp. Endocrinol. 63, $481-491$.

Wagner, G.F., DiMattia, G.E., Davie, J.R., Copp, D.H., Friesen, H.G., 1992. Molecular cloning and cDNA sequence analysis of coho salmon stanniocalcin. Mol. Cell. Endocrinol. 90, 7-15.

Wagner, G.F., Guiraudon, C.C., Milliken, C., Copp, D.H., 1995. Immunological and biological evidence for a stanniocalcin-like hormone in human kidney. Proc. Natl. Acad. Sci. USA 92, $1871-1875$

Wagner, G.F., Vozzolo, B.L., Jaworski, E., Haddad, M., Kline, R.L., Olsen, H.S., Rosen, C.A., Davidson, M.B., Renfro, J.L., 1997a. Human stanniocalcin inhibits renal phosphate excretion in the rat. J. Bone Miner. Res. 12, 165-171.

Wagner, G.F., De Niu, P., Jaworski, E., Radman, D., Chiarot, C., 1997b. Development of a dose response bioassay for stanniocalcin in fish. Mol. Cell. Endocrinol. 128, 19-28.

Wagner, G.F., Jaworski, E.M., Haddad, M., 1998. Stanniocalcin in the seawater salmon: structure, function, and regulation. Am. J. Physiol. 274, 1177-1185.

Wendelaar Bonga, S.E., Flik, G., Lowik, C.W., van Eys, G.J., 1985. Enviromental control of prolactin synthesis in the teleost fish Oreochromis (formerly Sarotherodon) mossambicus. Gen. Comp. Endocrinol. 57, 352-359.

Yamashita, K., Koide, Y., Itoh, H., Kawada, N., Kawauchi, H., 1995. The complete amino acid sequence of chum salmon stanniocalcin, a calcium-regulating hormone in teleosts. Mol. Cell. Endocrinol. 112, 159-167.

Youson, J.H., Butler, D.G., 1988. Morphology of the kidney of adult bowfin, Amia calva, with emphasis on 'renal chloride cells' in the tubule. J. Morphol. 196, 137-156.

Youson, J.H., Butler, D.G., Chan, A.T., 1976. Identification and distribution of the adrenocortical homolog, chromaffin tissue, and corpuscles of Stannius in Amia calva L. Gen. Comp. Endocrinol. 29, 198-211. 